\title{
PREDICTING DESISTANCE IN A HIGH-RISK SAMPLE: EXAMINING THE INFLUENCE OF INDIVIDUAL AND CONTEXTUAL FACTORS
}

Sophie M. Aiyer

University of Michigan

Joanna Lee Williams, Patrick H. Tolan, and Melvin N.

Wilson

University of Virginia

\section{BACKGROUND}

Delinquent behavior typically emerges in early adolescence, peaks in mid-adolescence, and decreases in early adulthood (Tremblay et al., 2004). The age crime-curve has been observed across crime categories, countries, and historical periods (Hirschi \& Gottfredson, 1983). Further, childhood antisocial behavior strongly predicts later antisocial behavior, yet not all children who display early behavioral problems continue to exhibit such behavior into adulthood (Moffitt, Caspi, Dickson, Silva, \& Stanton, 1996). Thus, adolescence becomes a critical period for determining whether a youth will persist in or desist from criminal behavior (Loeber \& Farrington, 2012).

Desistance is the process that results in the termination of antisocial behavior and criminal activity (Laub \& Sampson, 2001). As noted above, desistance typically takes place during late adolescence and early adulthood, irrespective of antisocial behavior onset (Loeber, Farrington, Stouthamer-Loeber, \& White, 2008). Desistance is likely to result from a range of complex developmental, psychological, and sociological processes (Laub \& Sampson, 2001). Although few theories exist to specifically explain desistance, both ecological and developmental-ecological perspectives have been applied to examining antisocial behavior in children and adolescents (Belsky, 1980; Bronfenbrenner, 1979;

Please address correspondence to: Sophie Aiyer, University of Michigan, Health Behavior Health Education, 1415 Washington Heights, 3706 SPH I, Ann Arbor, Michigan 48109. E-mail: sma8a@virginia.edu

JOURNAL OF COMMUNITY PSYCHOLOGY, Vol. 41, No. 4, 408-424 (2013)

Published online in Wiley Online Library (wileyonlinelibrary.com/journal/jcop).

(C) 2012 Wiley Periodicals, Inc. DOI: 10.1002/jcop.21545 
Tolan, Guerra, \& Kendall, 1995 ). Thus, we apply such theories to studying the desistance process.

Ecological theorists assert that human development and behavior evolve as a function of the interplay between the individual child and his or her social environment (Bronfenbrenner, 1979). From this perspective, child and parent characteristics as well as sociocultural and environmental factors are thought to influence parent-child relationships (Belsky, 1980). Developmental theorists propose that although antisocial behavior may be based on biological predisposition, vulnerability is exacerbated by environmental factors over time (Moffitt, 1990; Moffitt, Caspi, Harrington, \& Milne, 2002). Exposure to deleterious environments is thought to exacerbate existing behavioral problems (Sameroff, 2007; Miech, Caspi, Moffitt, Wright, \& Silva, 1999), thus at-risk children may be particularly sensitive to detrimental factors in both family and neighborhood contexts (Luthar \& Zigler, 1991).

Individual characteristics, particularly aggression and poor attention, have been consistently linked to the development of antisocial behavior. Childhood aggression is a strong predictor of juvenile delinquency, and is the individual feature most predictive of lifecourse persistent antisocial behavior (Dodge \& Pettit, 2003; Loeber \& Farrington, 2000). Furthermore, impulsivity demonstrates continuity with later antisocial behavior (Nagin \& Tremblay, 1999; Tremblay, Pihl, Vitaro, \& Dobkin, 1994), and childhood selfcontrol reduces risk for juvenile delinquency (Monahan, Steinberg, Cauffman, \& Mulvey, 2009). Early individual differences in aggression and self-control are also linked to criminal offending (Loeber \& Farringon, 2012). As desistance represents the termination of offending, these constructs may be related to desistance as well.

Developmental-ecological perspectives account for individual characteristics, as well as the influence of environmental factors in determining behavior. Further, family relationships influence adolescent antisocial behavior, and may also explain variation in desistance. Low parental involvement, weak family cohesion, and poor parent-child communication increase risk for delinquency (Capaldi \& Patterson, 1994; Gorman-Smith, Tolan, Zelli, \& Huesmann, 1996). Harsh and inconsistent discipline is also a strong predictor of antisocial behavior, along with poor supervision, weak monitoring, and lack of parent-child warmth (Patterson, Reid, \& Dishion, 1992; Dodge \& Pettit, 2003). In addition, stable marital relationships and family social bonds may predict desistance in adulthood (Sampson \& Laub, 1993). Desisters also report stronger, more positive family relationships than their persistent counterparts (van Domburgh, Loeber, Bezemer, Stallings, \& Stouthamer-Loeber, 2009). Social capital derived from family connections may explain the positive effects of family ties (Farrall \& Calverley, 2006). Family relationships are also thought to facilitate positive social action by generating a sense of responsibility and obligation to others (McCarthy \& Hagan, 2001).

Family history of antisocial behavior is a risk factor for juvenile delinquency and persistent offending (Lipsey \& Derzon, 1998). Family risk factors are likely to affect child outcomes through both genetic and environmental mechanisms. At-risk children are more likely to be exposed to environments that promote antisocial behavior; these children may also be particularly vulnerable to environmental factors based on their genetic predisposition (Lahey \& Waldman, 2005). Thus, children genetically predisposed to antisocial behavior may be at high risk for persistent offending because of both geneenvironment correlations and gene-environment interactions (Lahey \& Waldman, 2005). Such family factors are also considered stable over time, which amplifies their effect on both antisocial behavior onset and maintenance (Thornberry \& Krohn, 2005). 
Developmental and ecological theories emphasize how the social environment influences behavior, acknowledging the importance of both family and neighborhood settings. Neighborhood factors become increasingly influential during adolescence, as youth gain autonomy from parents during this period (Steinberg \& Morris, 2001; Dishion \& McMahon, 1998). Exposure to neighborhood disadvantage, crime, and violence all elevate risk for antisocial behavior (Coie \& Dodge, 1998; Lahey, Miller, Gordon, \& Riley, 1999). Exposure to neighborhood violence increases risk for adolescent antisocial behavior, even after controlling for childhood aggression (Gorman-Smith, 1999). Neighborhood disorganization and weak informal social control reduce a community's ability to regulate the behavior of adolescents (Sampson, Raudenbush, \& Earls, 1997), which may explain the prevalence of delinquency in low-income neighborhoods (Chen \& Patterson, 2006). Furthermore, desistance has been linked to both neighborhood disadvantage and crime density (Loeber \& Farrington, 2012), yet we still need a better understanding of how neighborhoods influence desistance.

Several gaps in our knowledge about desistance remain. Researchers have primarily focused on childhood predictors of antisocial behavior, rather than viewing later teenage and early adult years as critical periods of social and behavioral development (Loeber \& Farrington, 2012). As relatively few offenders continue offending during adulthood (Loeber \& Farrington, 2000; Moffitt, 1993), it is important to identify risk and promotive factors that distinguish youth who desist from those who continue to offend. To help us understand what prevents delinquency from evolving into persistent criminal behavior, the present study focuses on the transition from adolescence into young adulthood.

Researchers have traditionally tested ecological theories of antisocial behavior (Tolan, Gorman-Smith, \& Henry, 2003; Tolan, Guerra, \& Kendall, 1995), yet very few studies have taken an ecological approach to studying desistance from crime. Thus, we aim to improve our understanding about the direct and interactive influence of risk and promotive factors in individual, family, and neighborhood domains on desistance. Specifically, we examine whether risk from aggression varies based on individual levels of attention and parental discipline practices. We also test the interaction between discipline and mother's antisocial behavior, to examine whether genetic factors influence the effect of parenting behavior. Finally, we examine whether discipline practices moderate exposure to neighborhood violence, based on previous findings that family processes buffer risk from the broader environmental context (Gorman-Smith, Tolan, \& Henry, 2000; Tolan et al., 2003).

We chose a specialized sample of high-risk, inner-city delinquent males to test our hypotheses about desistance. Young men commit a large amount of offenses (Rutter, Giller, \& Hagell, 1998), and antisocial behavior is more common in males (Lahey et al., 2006; Moffitt, Caspi, Rutter, \& Silva, 2001). Delinquency and crime are also concentrated in disadvantaged neighborhoods (Odgers, Caspi, Bates, Sampson, \& Moffitt, 2012; Sampson et al., 1997), thus we focused on a low-income, inner-city sample of African American and Latino males. Compared with their Caucasian counterparts, low-income African American males exhibit a smaller decline in violent behavior during early adulthood (Coie, 2004; Elliot, 1994), supporting the rationale for selecting our sample. As early antisocial behavior is a risk factor for persistent behavioral problems (Moffitt et al., 2002), we also focused on youth who displayed signs of childhood aggression. We ultimately aim to further our knowledge about processes that promote desistance in order to create effective prevention and interventions strategies for low-income, high-risk, antisocial male youth. 


\section{RESEARCH QUESTIONS AND HYPOTHESES}

Poor attention and weak concentration are known to predict risk for later delinquency (Bor, McGee, \& Fagan, 2004), yet there is conflicting evidence for whether this effect is distinct from aggression (Moffitt, 2006). Aggression is also most strongly associated with delinquency when part of a constellation of behavioral problems including hyperactivity and inattention (Rutter et al., 1998). Thus, the first hypothesis is that individual characteristics (e.g., both aggression and poor attention) will be negatively associated with desistance. In addition, we predict that poor attention will be more detrimental for highly aggressive youth.

Social influences in the family context account for a considerable amount of antisocial behavior continuity, above and beyond individual predisposition (Laub \& Sampson, 2003; Sampson \& Laub, 1990). We hypothesize that family promotive factors (e.g., discipline practices and parental monitoring) will predict desistance. In addition, we hypothesize that mother's antisocial behavior will be negatively associated with desistance. As aggressive youth may be more sensitive to environmental influences (Moffitt et al., 2002), we predict that discipline will be a stronger promotive factor for the highly aggressive youth. Because of the effect of both genetic and environmental risk, poor parenting is likely to be more detrimental when parents are antisocial (Rutter et al., 1998). Thus, we hypothesize that discipline will be a stronger protective factor when mother's antisocial behavior is low.

Youth raised in low-income, inner-city neighborhoods may be at greater risk for chronic delinquency compared with those raised in lower-risk contexts (Wikstrom \& Loeber, 2000). We predict that neighborhood risk factors (e.g., exposure to violence) will be negatively associated with desistance, while neighborhood promotive factors (e.g., neighborhood resources and social processes) will promote desistance. We are interested in not only the direct effects of neighborhood factors but also their interaction with family factors. Our last set of hypotheses concerns the presence of cross-setting interactions between family and neighborhood factors. We hypothesize that the positive association between discipline and desistance will be stronger at low levels of neighborhood violence exposure.

\section{METHOD}

\section{Participants}

We analyzed data from the Chicago Youth Development Study (CYDS), an ongoing longitudinal study of the development of serious delinquent behavior among a sample of inner-city male adolescents (Tolan, 2009). Participants were initially recruited from the fifth and seventh grades of 17 Chicago public schools in 1990.

After obtaining parental permission, 1,105 boys ( $92 \%$ of boys in participating schools) were screened for behavior problems using the Achenbach Teacher Rating Form (TRF; Achenbach, 1991). Boys were selected for participation so that $50 \%$ were identified as "high risk" for the development of serious antisocial behavior based on their TRF Aggression Scale scores, indicating high levels of aggressive behavior at baseline $\left(T>70,98^{\text {th }}\right.$ percentile). Participants were randomly selected from the remainder of those screened and $75 \%$ of the eligible participants completed interviews during the first wave of data collection ( $n=341$; Gorman-Smith, Tolan, Loeber, \& Henry, 1998).

Sixty-three percent of participants were from single parent homes, $57 \%$ were African American, and $43 \%$ were Latino. Forty-eight percent came from families with a total family 
Table 1. Descriptive Statistics for Demographic and Key Study Variables by Desistance Category

\begin{tabular}{|c|c|c|c|c|c|c|c|c|c|c|}
\hline \multirow[b]{2}{*}{ Variable } & \multicolumn{5}{|c|}{ Desisters } & \multicolumn{5}{|c|}{ Persisters } \\
\hline & $N$ & Range & Minimum & $\operatorname{Max}$ & $\begin{array}{c}\text { Mean } \\
(S D)\end{array}$ & $N$ & Range & Minimum & $\operatorname{Max}$ & $\begin{array}{c}\text { Mean } \\
(S D)\end{array}$ \\
\hline Mother's education & 67 & 6 & 1 & 7 & $4.03(1.45)$ & 49 & 6 & 1 & 7 & $3.88(1.32)$ \\
\hline Age & 65 & 5 & 10 & 15 & $12.51(1.21)$ & 49 & 5 & 10 & 15 & $12.51(1.18)$ \\
\hline Aggression & 75 & 2.25 & 1.44 & 3.68 & $2.29(.47)$ & 60 & 2.44 & 1.54 & 3.98 & $2.51(.48)$ \\
\hline Poor attention & 75 & 2.37 & 1 & 3.37 & $2.00(.49)$ & 60 & 1.78 & 1.22 & 3.00 & $2.08(.42)$ \\
\hline Monitoring & 75 & 1.65 & -1.13 & .52 & $-.03(.31)$ & 60 & 1.54 & -1.06 & .48 & $-.07(.33)$ \\
\hline Discipline & 75 & 1.29 & -.48 & .82 & $.08(.24)$ & 60 & 1.36 & -.70 & .67 & $.03(.29)$ \\
\hline Mother's AB & 75 & 1.41 & 0 & 1.41 & $.68(.32)$ & 60 & 1.73 & 0 & 1.73 & $.80(.39)$ \\
\hline Social processes & 75 & 1.82 & 2.15 & 3.97 & $3.09(.37)$ & 60 & 1.89 & 2.11 & 4.00 & $3.00(.40)$ \\
\hline Resources & 75 & 2.02 & .31 & 2.34 & $1.40(.49)$ & 60 & 1.71 & .53 & 2.23 & $1.37(.43)$ \\
\hline ETV & 75 & 1.11 & 0 & 1.11 & $.51(.26)$ & 60 & 1.00 & 0 & 1.00 & $.55(.23)$ \\
\hline Valid $N$ & 61 & & & & & 43 & & & & \\
\hline
\end{tabular}

Note. Max = maximum; $\mathrm{SD}=$ standard deviation; monitoring $=$ parental monitoring; discipline $=$ discipline practices; mother's $\mathrm{AB}=$ mother's antisocial behavior; social processes = neighborhood social processes; resources $=$ neighborhood resources; ETV = exposure to violence.

income of under $\$ 10,000$ per year, and $74 \%$ had a total family income of under $\$ 20,000$ per year. Participants were between the ages of 10 and 15 years at Wave 1 (mean $[M]=$ 12.3; standard deviation $[S D]=1.3)$, and between 17 and 22 years of age at Wave $6(\mathrm{M}=$ $19.6 ; \mathrm{SD}=1.4$ ).

\section{Analytic Sample}

Using data from the Self-Report Delinquency scale (SRD; Elliot, Dunford, \& Huizinga, 1987), and composite scores from the externalizing subscales of the Child Behavior Checklist (Achenbach, 1991), participants were classified into four trajectories that described patterns of offending over time: "nonoffenders" displayed little to no aggression over time $(25.2 \%, n=66)$; "chronic minor offenders" displayed minor antisocial acts and aggression at every wave, but no serious delinquency or violence $(34 \%, n=89)$; "escalating offenders" displayed less delinquent acts at earlier waves with escalation to violence and/ or serious antisocial behavior during later waves $(13.4 \%, n=35)$; and "serious chronic and violent offenders" displayed high levels of serious antisocial behavior and increasing violence across all four waves $(27.5 \%, n=72$; Gorman-Smith, Tolan, Loeber, \& Henry, 1998).

As previously mentioned, nonoffenders displayed minimal to no delinquent behavior across all waves. As desistance is defined as the sustained absence of criminal offending, the non-offender group was omitted from our analytic sample. Analyzing data from the remaining three delinquency groups facilitated an investigation of what factors distinguished participants who desisted from crime from those who continued to offend. Thus, the present study included 196 of the original 262 CYDS participants. In Table 1, descriptive statistics for key demographic variables are presented for the nonoffenders (who were excluded), followed by the three groups retained. The nonoffenders were slightly younger than there delinquent counterparts in Wave 1, and also had mothers with slightly higher levels of education. As shown in Table 1, the mean age of boys in the analytic sample was $12.5(\mathrm{SD}=1.2)$ years at Wave 1 and $19.6(\mathrm{SD}=1.4)$ years at Wave 6 . 
Of the 196 participants in the current study, data were missing on key study variables for 78 participants. Specifically, data were missing for the ethnicity, mother's education, and desistance variables. The data were examined for lack of normality, lack of linearity, and outliers by examining basic statistics and bivariate correlations. Assumptions of normality were met for the ethnicity and mother's education variables, and multiple imputations for missing data were performed. Five data sets were created with imputed data. Data sets were analyzed separately, after which results were pooled and compared with the original findings. The pooled analyses yielded similar results to the original findings, and we determined that the data on the ethnicity and the mother's education variables were missing at random. Finally, listwise deletion was used to handle missing data on the outcome variable. Although the listwise deletion method inevitably decreased our statistical power, we were more concerned about introducing biased estimates of missing coefficients by imputing outcome data. Imputing missing outcome data introduces most bias when outcomes are measured across more than one time point (Sterne et al., 2009). Following treatment of missing data, the sample size was 136.

\section{Measures}

Desistance. Participants were questioned about frequency of involvement in 38 criminal acts (including drug and alcohol use) over the past year using the modified SRD scale (Elliot et al., 1987). The SRD assesses both the amount and type of antisocial, delinquent, and violent behavior participants engaged in, with status offenses being the least serious, and class 1 felonies being the most serious (Gorman-Smith, Tolan, \& Henry, 1999). Based on SRD scores (Elliot et al., 1987; Tolan et al., 2002), participants were then assigned a "delinquency" score calculated by multiplying the frequency of each delinquent act by its corresponding legal severity weight. Scores ranged from 0 to 4 with higher scores representing both a higher frequency and a higher level of legal severity. In the present study, delinquency scores from Waves 5 and 6 (corresponding to 16-22 years of age) were used to assess desistance. Desistance was defined as minimal to no engagement in antisocial behavior in both Waves 5 and 6 . Participants who received a score of 0 in both waves were labeled as desisters and given a score of 1 . Participants who received a score between 1-4 were labeled as persisters and given a score of 0 . Operationalizing desistance as a dichotomous variable preserved the definition of desistance as the absence of antisocial behavior, instead of defining it as relatively less participation in antisocial behavior.

Aggression. Aggression was measured using the Aggressive Behavior subscale scores from the Externalizing scale of the CBCL. The Child Behavior Checklist for Ages 4-18 (CBCL/4-18; Achenbach, 1991) comprises eight subscales that measure social withdrawal, somatic complaints, anxiety and depression, social problems, thought problems, attention problems, delinquent behavior, and aggressive behavior. Items assessing aggression include "You argue a lot." Mean scores were taken across Waves 1-4 of the parent and child reports.

Poor attention. Poor attention was measured using the Attention Problem subscale scores from the Externalizing scale of the CBCL (CBCL/4-18; Achenbach, 1991). Items assessing attention problems include, "you have trouble concentrating or paying attention." Mean scores were taken across Waves 1-4 of the parent and child reports. 
Discipline practices. The Parenting Practices Measure (PPS; Gorman-Smith, Tolan, Zelli, \& Huesmann, 1996; Tolan et al., 2000) was derived from the Parental Supervision And Discipline Interview used in the Oregon Youth Study and Pittsburgh Youth Study (Thornberry, Huizinga, \& Loeber, 1995). The PPS measures three major aspects of parenting practices: (a) positive parenting, (b) extent of monitoring and involvement, and (c) discipline effectiveness. Discipline effectiveness refers to how effective parental discipline is in controlling the child's behavior. Avoidance of discipline measures the parent's disengagement and avoidance of providing consequences for fear of escalating the child's behavior (Tolan et al., 2000). All items in the parenting subscales were scored so that high scores indicated positive parenting. A confirmatory factor analysis (CFA; Gorman-Smith et al., 1996) was conducted to determine the appropriate factor structure for the parenting measures (Tolan et al., 2000). ${ }^{1}$ Based on the CFA results, scores from the discipline effectiveness and avoidance subscales of the PPS (parent-report) were combined to assess the final weighted discipline practices construct, which was averaged across Waves 1-4 for the present study. ${ }^{2}$

Parental monitoring. Parental monitoring was estimated from taking mean scores across Waves 1-4 using the final weighted parental monitoring construct, based on previous results of a confirmatory factor analysis (see footnote 3$){ }^{3}$

Mother's antisocial behavior. Mothers were asked about their engagement in delinquent behavior during the last year using the SRD described above (Elliot et al., 1987; Tolan et al., 2002). Mothers were assigned a "delinquency" score calculated by multiplying the frequency of each act by its legal severity weight (Tolan et al., 2002). Mean scores were taken across Waves 1-4 to estimate mothers' antisocial behavior.

Neighborhood social processes. Social processes were assessed with data from mothers' and sons' reports of neighborliness and extent of neighborhood problems (Gorman-Smith et al., 2000; Tolan et al., 2003). Neighborliness refers to the extent to which participants see themselves as involved with and able to depend on other community members. Three scales were used as indicators of neighborliness: (a) sense of belonging, (b) social support, and (c) community involvement (parent-report only). Neighborhood problems were assessed using the Extent of Neighborhood Problems scale, which measures the degree to which participants perceive crime as problematic. Participants were asked whether graffiti, noise, drugs, abandoned buildings, vandalism, burglary, homelessness, gangs, and violent crime were problems in their neighborhood. Mean scores were taken across Waves 1-4 to estimate neighborhood social processes.

\footnotetext{
${ }^{1}$ The CFA results were consistent with other CYDS papers in identifying latent constructs of Discipline and Monitoring (Gorman-Smith et al., 1996; Sheidow, 2000). In order to develop weightings for factor score computations, the CFA was conducted using wave 2 data. The model was a good fit to the data $\left(X^{2}(7)=12.99\right.$, $p=.07 ; X^{2}$ : Degrees of Freedom = 1.9; Root Mean Square Error of Approximation = .055; Goodness of Fit $=$ .98 ; Adjusted Goodness of Fit $=.95$ ) (Sheidow, 2000). Next, factor score regression coefficients were obtained using Lisrel in order to generate weightings for the indicator scales; regression coefficients were subsequently used to compute weighted scores for each latent factor. Finally, the unstandardized regression coefficients from the Lisrel analysis were used as the final weightings in creating scores for both Monitoring and Discipline.

${ }^{2}$ The final weighted Discipline construct was calculated with the following equation: $1.385+$ (Mother Avoidance $\times-0.676)+($ Mother Discipline Effectiveness $\times 0.879)$ (Tolan et al., 2000).

${ }^{3}$ The final weighted Monitoring construct was calculated with the following equation: $0.040+$ (Youth Extent of Involvement $\times 0.009)+($ Youth Positive Parenting $\times 0.072)+($ Caregiver Extent of Involvement $\times 1.090)+$ $($ Caregiver Positive Parenting $\times 0.385)+($ Caregiver Avoidance $\times 0.262)$ (Sheidow, 2000)
} 
Neighborhood resources. Neighborhood resources were assessed with items from the Community and Neighborhood Measure (Tolan et al., 2001). This measure was derived from Elliot and colleagues' neighborhood study measure (Elliot et al., 1996). Subscales measuring resource availability and use were used. Items were selected to reflect the political economy of the neighborhood (Tolan \& Gorman-Smith, 1993), such as "There is a grocery store in or near my neighborhood." Mean scores were taken across Waves 1-4 to assess neighborhood resources.

Exposure to violence. Exposure to violence (ETV) was assessed as a total frequency count for six events from the Exposure to Violence Interview, a subscale of the stress and coping measure (Brady, Gorman-Smith, Henry, \& Tolan, 2008; Tolan \& Gorman-Smith, 1992). Participants were asked if they had ever witnessed events related to witnessing violence and victimization during the last year, such as "Anyone in your family was robbed or attacked (beaten up, raped, or hurt by someone),"You saw anyone shot or killed," and "You were the victim of any violent crime involving force or threat of force." Mean scores were taken across Waves 2-4 to estimate ETV; data on exposure to street violence were not collected in Wave 1.

Control variables. Data on ethnicity were obtained from both mother and son reports on ethnic group. Ethnicity was measured as a dichotomous variable, such that African American participants were assigned a score of 0 , and Latino participants were assigned a score of 1. Mother's education was assessed at baseline and used as a proxy for socioeconomic status.

\section{RESULTS}

\section{Overview of Analytic Strategy}

We selected control variables first to reduce potential confounding. Results from a one-way analysis of variance indicated that both ethnicity and mother's education demonstrated subgroup differences in predicting desistance. Yet there were no significant differences based on age. Thus, we retained ethnicity and mother's education as control variables. Next, we evaluated skewness of the study variables. In addition, we examined bivariate correlations among study variables to determine whether there were issues of multicollinearity present. Following the preliminary analyses, hypotheses were tested using a series of stepwise binary logistic regression models. Control variables were entered at step 1 for all regression analyses. Individual characteristics (e.g., aggression and poor attention) were entered at step 2. Family factors (e.g., discipline practices, parental monitoring, and mother's antisocial behavior) were entered at step 3. Neighborhood factors (e.g., neighborhood social processes, neighborhood resources, and ETV) were entered at step 4. Interactions between individual, family, and neighborhood processes were entered at step 5. Specifically, aggression was tested as a moderator of poor attention on desistance. Next, we tested whether discipline buffered risk from aggression on desistance. Finally, we tested whether mother's antisocial behavior and ETV moderated the effects of discipline practices.

Means and standard deviations. The means and standard deviations for all key study variables are presented in Table 2. Descriptive statistics reflect our samples' high-risk nature. 
Table 2. Descriptive Statistics for Key Study Variables

\begin{tabular}{|c|c|c|c|c|c|}
\hline & $N$ & Mean (SD) pre-T & Skewness pre-T & Range pre-T & Range post- $T$ \\
\hline \multicolumn{6}{|l|}{ Variable } \\
\hline Aggression & 196 & $6.28(2.57)$ & $.87(.17)$ & $2.07-15.87$ & $1.44-3.98$ \\
\hline Poor attention & 196 & $4.54(2.12)$ & $1.18(.17)$ & $1.00-12.50$ & $1.00-3.54$ \\
\hline Discipline & 196 & $.08(.27)$ & $-.014(.17)$ & $-.79-.82$ & - \\
\hline Monitoring & 196 & $-.07(.32)$ & $-.75(.17)$ & $-1.15-.52$ & - \\
\hline Mother's AB & 196 & $.75(.61)$ & $1.14(.17)$ & $0-3.00$ & $0-1.73$ \\
\hline Social processes & 196 & $3.04(.39)$ & $.04(.17)$ & $2.11-4.04$ & - \\
\hline Resources & 196 & $1.38(.46)$ & $-.06(.17)$ & $0.31-2.34$ & - \\
\hline ETV & 196 & $0.38(.26)$ & $.86(.17)$ & $0-1.33$ & $0-1.15$ \\
\hline Desistance & 136 & $0.55(.50)$ & $-.21(.21)$ & $0-1$ & - \\
\hline Valid N & 136 & & & & \\
\hline
\end{tabular}

Note. $\mathrm{T}=$ transformation; discipline $=$ discipline practices; monitoring $=$ parental monitoring; mother's $\mathrm{AB}=$ mother's antisocial behavior; social processes $=$ neighborhood social processes; resources $=$ neighborhood resources; ETV $=$ exposure to violence. To reduce skewness, aggression, impulsivity, mother's AB and exposure to violence variables were transformed using a square root transformation. The remaining variables listed were not transformed.

Aggression, poor attention, mother's antisocial behavior, and ETV all had a moderate right skew. Therefore, we performed a square root transformation to normalize the variables.

Intercorrelations. After calculating descriptive statistics, we examined bivariate correlations among the study variables. Correlation analyses revealed that about half of the associations were nonsignificant. The associations that were statistically significant were typically small, suggesting few issues of overlap. We also examined collinearity statistics, and all tolerance statistics were over .40, indicating no issues with multicollinearity present. (Cohen, Cohen, West, \& Aiken, 2003).

\section{Analytic Models-Main Effects}

Individual characteristics. After entering the control variables, aggression and poor attention were entered to test whether they were associated with desistance. As shown in Table 3, aggression measured across adolescence was a strong negative predictor of desistance in young adulthood $(\beta=-1.63, p<.01)$. Indicated in by the odds ratio (odds ratio $=.20)$, for each unit increase in the aggression score, the odds of desistance decreased from 1.0 to .20 . Poor attention was not associated with desistance.

Family factors. Discipline practices, parental monitoring, and mother's antisocial behavior were entered next to examine whether family characteristics influenced desistance. As shown in Table 3, discipline measured across adolescence was a strong positive predictor of desistance in young adulthood $(\beta=2.62, p<.01)$. For each unit increase in the discipline, the odds of desistance increased from 1.0 to 13.72. Also as predicted, mother's antisocial behavior was negatively associated with desistance $(B=-1.44, p<.01)$. For each unit increase in mother's antisocial behavior, the odds of desistance decreased from 1.0 to .24. Parental monitoring was not a significant predictor.

Neighborhood factors. Neighborhood social processes, neighborhood resources, and ETV were entered next to examine the role of neighborhood factors in predicting desistance. As shown in Table 3, social processes and resources were not significantly associated with 
Table 3. Binary Logistic Regression Results Demonstrating All Main Effects and Interactions

\begin{tabular}{|c|c|c|c|c|c|c|c|}
\hline \multirow{2}{*}{$\begin{array}{l}\begin{array}{l}\text { Regression } \\
\text { step }\end{array} \\
\begin{array}{c}\text { Step 1: Co- } \\
\text { variates }\end{array}\end{array}$} & \multirow[t]{2}{*}{ Variable } & \multirow[t]{2}{*}{$\begin{array}{c}B \\
(S E)\end{array}$} & \multirow[t]{2}{*}{$\begin{array}{c}B(S E) \\
\text { final step }\end{array}$} & \multirow[t]{2}{*}{$O R$} & \multirow[t]{2}{*}{ Probability } & \multicolumn{2}{|c|}{$\begin{array}{c}95 \% C I \\
\text { for } \exp (B)\end{array}$} \\
\hline & & & & & & Lower & Upper \\
\hline & Ethnic Group & $-.13(.18)$ & $.02(.21)$ & 1.14 & $53.3 \%$ & .81 & 1.6 \\
\hline & Mother's Ed & $.01(.13)$ & $-.03(.17)$ & 1.01 & $50.2 \%$ & .79 & 1.3 \\
\hline \multicolumn{8}{|l|}{$\begin{array}{l}\text { Step 2: } \\
\quad \text { Indiv Fx }\end{array}$} \\
\hline & Aggression & $-1.63(.54)^{* *}$ & $-.49(.64)$ & .20 & $16.7 \%$ & .07 & .57 \\
\hline & Poor Attention & $.33(.52)$ & $-.40(.59)$ & 1.40 & $58.3 \%$ & .50 & 3.88 \\
\hline \multicolumn{8}{|l|}{$\begin{array}{l}\text { Step 3: } \\
\text { Family } \\
\text { Fx }\end{array}$} \\
\hline & Discipline & $2.62(.91)^{* *}$ & $2.8(.92)^{* *}$ & $13.72(16.51)$ & $93.2 \%$ & 2.31 & 81.53 \\
\hline & Monitoring & $-.00(.66)$ & $-.10(.67)$ & $.99(.90)$ & $49.7 \%$ & .27 & 3.64 \\
\hline & Mother AB & $-1.44(1.45)^{* *}$ & $-1.29(.67)^{*}$ & $.24(.28)$ & $19.4 \%$ & .07 & .84 \\
\hline \multicolumn{8}{|l|}{$\begin{array}{l}\text { Step 4: } \\
\text { Nbrhd } \\
\text { Fx }\end{array}$} \\
\hline & SocialProc & $-.14(.67)$ & $-.14(.67)$ & 1.15 & $53.5 \%$ & .38 & 3.50 \\
\hline & Resources & $.40(.47)$ & $.40(.47)$ & 1.49 & $59.8 \%$ & .59 & 3.77 \\
\hline & ETV & $-1.90(.97)^{*}$ & $-1.90(.97)^{*}$ & .15 & $13.0 \%$ & .02 & .99 \\
\hline \multicolumn{8}{|l|}{$\begin{array}{l}\text { Step 5: In- } \\
\text { teract's }\end{array}$} \\
\hline & Att $\times$ Agg & $-.19(.77)$ & $\backslash$ & .83 & $45.4 \%$ & .18 & 3.76 \\
\hline & Agg $\times$ Disc & $-.80(.42)^{*}$ & $\backslash$ & .45 & $31.0 \%$ & .20 & 1.03 \\
\hline & MoAB $\times$ Disc & $-2.32(1.75)$ & $\backslash$ & .10 & $9.1 \%$ & .01 & 2.99 \\
\hline & Disc $\times$ ETV & $1.02(5.0)$ & & 2.77 & $73.5 \%$ & .00 & 49450.79 \\
\hline
\end{tabular}

Note. $\mathrm{SE}=$ standard error; $\mathrm{OR}=$ odds ratio; $\mathrm{CI}=$ confidence interval; Indiv Fx = Individual Factors, Family Fx $=$ Family Factors, Nbrhd Fx = Neighborhood Factors, Interact's = Interactions; Mother's Ed = Mother's Education; Discipline $=$ Discipline Practices, Monitoring $=$ Parental Monitoring, Mother $\mathrm{AB}=$ Mother's antisocial behavior; ETV $=$ Exposure to Violence, Resources $=$ Neighborhood Resources, SocialProc $=$ Neighborhood Social Processes; Att $\mathrm{x}$ Agg $=$ Poor Attention $\times$ Aggression interaction term, Agg $\times$ Disc $=$ Aggression $\times$ Discipline interaction term, MoAB $\times$ Disc $=$ Mother's antisocial behavior $\times$ Discipline interaction term, Disc $\times$ ETV $=$ Discipline $\times$ Exposure to Violence interaction term.

${ }^{*}=p<.05 .^{* *}=p<.01 .^{* * *}=p<.001$.

desistance. As predicted, ETV was negatively associated with desistance $(B=-1.90, p<$ $.05)$. For each unit increase in the ETV score, the odds of desistance decreased from 1.0 to .15 .

Our main effects assessed the direct effects of aggression, poor attention, discipline practices, parental monitoring, mother's antisocial behavior, neighborhood social processes, neighborhood resources, and ETV on odds of desisting from crime. As shown in Table 3, there were a total of eight main effects tested (discounting control variables). When individual, family, and neighborhood factors were entered together in step 4, discipline was the strongest predictor of desistance, recording an odds ratio of $16.51(\beta=2.8$, $p<.01)$. Thus, for one unit increase in discipline, the odds of desistance increased from 1.0 to 16.51 . Mother's antisocial behavior also retained significance in the final step of the model, recording an odds ratio of .28 $(B=-1.29, p<.05)$. For one unit increase in mother's antisocial behavior, the odds of desistance decreased from 1.0 to .28. Aggression was no longer a significant predictor after family factors were accounted for. 


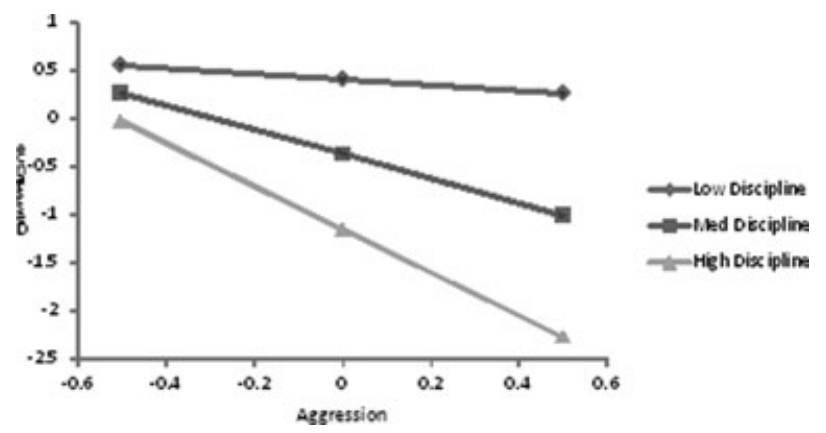

Figure 1. Demonstrates association between individual aggression score ( $x$-axis) and odds of desistance ( $y$-axis), at low, medium, and high levels of parental discipline.

Interactions. As shown in Table 3, we tested four one-way interactions at step 5. First, we tested whether aggression was a moderator of the association between poor attention and desistance. Contrary to the hypotheses, there was no significant interaction between aggression and poor attention. Next, we tested whether discipline moderated the effect of aggression on desistance. As predicted, there was a significant interaction between aggression and discipline. These results are described in more detail below. The interactions between discipline and mother's antisocial behavior and between ETV and discipline were nonsignificant.

To probe the interaction between discipline practices and aggression, we centered the predictors and examined the association between aggression and desistance at high and low levels of parental discipline (Aiken \& West, 1991). High levels of discipline were defined as one standard deviation above the mean, and low levels were defined as one standard deviation below the mean. The results shown in Figure 1 indicate an unanticipated pattern following. At high levels of discipline, the association between aggression and desistance was statistically significant, but it was not at low levels of discipline. Further, at medium to high levels of discipline, aggression was negatively associated with desistance. This finding suggests that discipline was a risk factor for persistence in highly aggressive youth. This contradicted our initial prediction that discipline practices would promote desistance in aggressive youth.

\section{DISCUSSION}

The present study deviates from traditional literature, which focuses on childhood predictors of adolescent antisocial behavior. Instead, we examine how factors during adolescence contribute to desistance in early adulthood. Previous studies on desistance have typically focused on either individual predictors or on social factors; however, we take an ecological approach to studying desistance, looking at multiple domains simultaneously. Further, we focused on a specialized sample of low-income, urban males selected for being at high-risk for antisocial behavior. From a public health perspective, we considered it important to identify factors contributing to desistance in a population at high relative risk for persistent offending.

In sum, we found evidence for the roles of aggression, discipline practices, mother's antisocial behavior, and ETV measured across adolescence in predicting desistance. We also found a significant interaction between aggression and discipline, the direction of 
which was counter to our predictions. The present findings ultimately emphasize the importance of identifying both individual and contextual factors that promote desistance in low-income, urban males.

\section{Predictive Ecological Factors}

Individual characteristics. Our findings are consistent with previous research suggesting that persistent offenders can be identified based on childhood aggression (Moffitt, 1993), and extend those findings to desistance. Children who face contextual adversity are thought to experience greater levels of arousal that ultimately manifest in aggressive behavior (Agnew, 1992). In our initial examination of zero-order correlations, aggression was moderately correlated with both mother's antisocial behavior and ETV. This emphasizes the idea that children exposed to environmental hardship may experience psychological stress, which manifests in aggressive behavior. Conversely, low levels of aggression are likely to explain later desistance because of both behavioral continuity and changes in the social environment over time (Farrington, 2003; Sampson \& Laub, 2003). In addition to the stability in individual traits over time, less aggressive boys may have also experienced more positive social relationships, and more success in various domains, thus promoting the likelihood of desistance. This underscores the role of transactional processes between boys and their environments in determining behavioral outcomes in early adulthood.

Family factors. Parental behavior is consistently associated with the development of antisocial behavior (Shaw, Criss, Schonberg \& Beck, 2004), and parent-child relationships are known to change during adolescence (McGue, Elkins, Walden, \& Iacono, 2005). Thus, we examined the roles of discipline practices, parental monitoring, and mother's antisocial behavior during adolescence. Consistent with our hypotheses, discipline practices increased the likelihood of later desistance. Furthermore, discipline was the strongest predictor of desistance overall, and maintained significance after neighborhood factors were considered. Our findings are consistent with previous studies demonstrating a link between exposure to neglectful parenting, harsh and inconsistent discipline, family conflict, and life-course persistent antisocial behavior (Moffitt \& Caspi, 2001; Patterson et al., 1992). We build on these findings by demonstrating that discipline also predicts later desistance in a low-income, urban male sample. The association between positive discipline practices and later desistance is consistent with literature on the stability of family attributes over the life course (Sampson \& Laub. 1993). Further, boys who are exposed to consistent, positive parenting at home may be more likely to form positive relationships outside of the home, thus making them more likely to desist. In addition, child effects on parenting practices (Bell \& Harper, 1997) may also influence the desistance process, such that less aggressive boys may elicit positive parenting behavior. In sum, we find evidence for the role of parenting in determining long-term outcomes, particularly during the transition from adolescence to adulthood.

Considering the importance of genes in transmitting antisocial behavior (Jaffee, Moffitt, Caspi, \& Taylor, 2004), we included mother's antisocial behavior in our model. This was done to better understand the role of genetic factors in the context of putative environmental factors. Consistent with our hypotheses, mother's antisocial behavior during adolescence decreased the likelihood of later desistance. Although previous studies have shown that parental antisocial behavior increases risk for delinquency, the mechanisms that explain this association remain unclear. Antisocial parenting characteristics may be transmitted to youth though genetic mechanisms, through parenting behaviors or through behavioral modeling (Jaffee et al., 2007; Farrington \& Welsh, 2007). 
Furthermore, antisocial behavior has been shown to be moderately heritable (Jaffee et al., 2004); thus, youth with antisocial mothers are likely to be exposed to both genetic and environmental risk factors (Jaffee et al., 2004). Further, boys raised with less antisocial mothers may be exposed to less genetic and environmental risk over time, increasing their chances of desisting in early adulthood.

Neighborhood factors. As predicted, ETV during adolescence negatively affected desistance in early adulthood. Our finding is consistent with previous evidence for a link between exposure to environmental stress and delinquency (Hofman \& Cerbone, 1999), and extends those findings to desistance. General strain theory (Agnew, 1992) offers one explanation for the role of ETV, suggesting that negative life experiences increase anger, which increases the likelihood of antisocial behavior. Likewise, boys exposed to less neighborhood violence may have also experienced fewer structural and social risk factors, thus explaining the link between lower levels of ETV and later desistance. Contrary to our hypotheses, neither neighborhood social processes nor resources were significant predictors. In disadvantaged, high-crime neighborhoods participants sometimes report less neighborhood involvement, less perceived social support, and a lower sense of neighborhood belonging (Tolan et al., 2003). As our participants were recruited from low-income, inner-city neighborhoods, variation in both social processes and resources may have also been too low to affect desistance.

\section{Dynamic Processes Impacting Desistance}

We predicted that the effect of aggression on desistance would be differentially moderated by discipline practices. Although this was the case, the direction of the association was not as hypothesized. In fact, discipline was a risk factor for persistence in the aggressive males. Thus, parental discipline may play a complex role in the lives of aggressive, urban, male youth.

Our discipline construct was measured such that higher scores indicated harmonious parent-child communication about rules and standards (Tolan et al., 2000). Conversely, low scores were somewhat characteristic of authoritarian parenting (e.g., more harsh discipline and less warmth). Dodge, Coie, and Lynam (2008) have shown that African American children perceive punitive parenting more positively than do European American children. This might be because punitive parenting is more normative in African American families; thus, children may be less likely to interpret such parenting as a sign of rejection. Harsh parenting is more strongly associated with childhood aggression in European American families, compared with African American families (Deater-Deckard, Dodge, Bates, \& Pettit, 1996). Authoritarian parenting may benefit low-income, ethnic minority youth, because this type of parenting protects youth from dangerous neighborhood surroundings (Furstenberg, Cook, Eccles, Elder, \& Sameroff, 1999). Further, Steinberg, Blatt-Eisengart, and Cauffman (2006) demonstrated that indulgent parenting was actually predictive of persistent offending. In the present study, harsh parenting may have promoted desistance in highly aggressive male youth because of the aforementioned reasons.

\section{Limitations}

As discussed, the present sample was particularly high-risk. Subsequently, there was lower variation in our study variables than we would have found with a normative sample. Also, 
because of the demographics of our sample, conclusions should not be drawn for females, for racial/ethnic groups besides African Americans and Latinos, or for nonurban, more advantaged populations. In addition, we had limited statistical power because of our relatively small sample size, and the narrow statistical range of our outcome variable. Yet this limited power emphasizes the importance of those effects that we did find. Finally, although we were interested in the role of genes in influencing desistance, we were unable to test gene-environment interactions in the present study.

\section{Conclusion}

Researchers have traditionally focused on critical transitions for children and adolescents. Yet understanding antisocial behavior in emerging adulthood is especially important considering the increasing societal demands that young adults face. Further, we took an ecological approach to studying desistance, rather than merely focusing one on domain of interest. Our findings emphasize the long-term influence of family factors, suggesting that programs designed to improve parent-child dynamics would benefit at-risk youth. As we focused on predicting desistance in a low-income, urban male sample, implications can be drawn for similar populations living in persistent poverty. Populations such as ours are exposed to a multitude of associated risk factors, making it critical to focus public health prevention efforts in disadvantaged communities. Finally, our findings suggest that prevention efforts should be devoted to aggressive, male youth living in stressful family and neighborhood contexts.

\section{REFERENGES}

Achenbach, T. M. (1991). Manual for the Child Behavior checklist/ 4-18 and 1991 Profile. Burlington, VT: University of Vermont, Department of Psychiatry.

Agnew, R. (1992). Foundations for a general strain theory of crime and delinquency. Criminology, $30,47-47$.

Aiken, L. S., \& West, S. G. (1991). Multiple regression: Testing and interpreting interactions. Newbury Park, VA: Sage.

Brady, S. S., Gorman-Smith, D., Henry, D. B., \& Tolan, P. H. (2008). Adaptive coping reduces the impact of community violence exposure on violent behavior among African American and Latino male adolescents. Journal of Abnormal Child Psychology, 36, 105-115.

Bronfenbrenner, U. (1979). The ecology of human development: Experiments by nature and design. Cambridge, MA: Harvard University Press.

Caspi, A., \& Moffitt, T. E. (1992). The continuity of maladaptive behavior: From description to understanding in the study of antisocial behavior. In D. Cicchetti \& D. Cohen (Eds.), Manual of developmental psychology. New York, NY: Wiley.

Cohen, J., Cohen, P., West, S. G., \& Aiken, L. S. (2003). Applied multiple regression/correlation analysis for the behavioral sciences. Mahwah, NJ: Lawrence Erlbaum Associates, Publishers.

Coie, J. D., \& Dodge, K. A. (1998). Aggression and antisocial behavior. In W. Damon \& N. Eisenberg (Eds.), Handbook of child psychology: Social, emotional, and personality development. New York, NY: Wiley.

Deater-Deckard, K., Dodge, K. A., Bates, J. E., \& Pettit, G. S. (1996). Physical discipline among African-American and European- American mothers: Links to children's externalizing behaviors. Developmental Psychology, 32, 1065-1072.

Dishion, T. J., \& McMahon, R. J. (1998). Parental monitoring and the prevention of child and adolescent problem behavior: A conceptual and empirical formulation. Clinical Child and Family Psychology Review, 1, 61-75. 
Dodge, K. A., Coie, J., \& Lynam, D. (2008). Aggression and antisocial behavior in youth. In W. Damon \& R. Lerner (Eds.), Child and adolescent development: An advanced course (pp. 437-472). New Jersey, NJ: John Wiley \& Sons.

Dodge, K. A., \& Pettit, G. S. (2003). A biopsychosocial model of the development of chronic conduct problems in adolescence. Developmental Psychology, 39, 349-371.

Elliot, D. S. (1994). Serious violent offenders: Onset, developmental course, and termination- The American Society of Criminology 1993 Presidential Address. Criminology, 32, 1-21.

Elliot, D. S., Dunford, F. W., \& Huizinga, D. (1987). The identification and prediction of career offenders utilizing self-reported and official data. In G. W. Albee \& J. M. Joffee (Series Eds.), Primary prevention of psychopathology, Volume 10. Newbury Park, CA: Sage.

Elliot, D. S., Wilson, W. J., Huizinga, D., Sampson, R. J., Elliot, A., \& Rankin, B. (1996). The effects of neighborhood disadvantage on adolescent development. Journal of Research in Crime and Delinquency, 33, 389-426.

Farrall, S., \& Calverley, A. (2006). Understanding desistance from crime. London, UK: Open University Press.

Farrington, D., \& Welsh, B. (2007). Saving children from a life of crime. New York, NY: Oxford University Press.

Fuhrman, T., \& Holmbeck, G. N. (1995). A contextual-moderator analysis of emotional autonomy and adjustment in adolescence. Child Development, 66, 793-811.

Furstenberg, F. F., Cook, T. D., Eccles, J., Elder, G. H., \& Sameroff, A. (1999). Managing to make it: Urban families and adolescent success. Chicago, IL: University of Chicago.

Gorman-Smith, D., Tolan, P. H., \& Henry, D. (1999). The relation of community and family to risk among urban-poor adolescents. In P. Cohen \& C. Slomkowski (Eds.), Historical and geographical influences on psychopathology (pp. 349-367). Mahwah, NJ: Lawrence Erlbaum.

Gorman-Smith, D., Tolan, P. H., \& Henry, D. (2000). A developmental-ecological model of the relation of family functioning to patterns of delinquency. Journal of Quantitative Criminology, $16,169-198$.

Gorman-Smith, D., Tolan, P., Loeber, R., \& Henry, D. (1998). Relation of family problems to patterns of delinquent involvement among urban youth. Journal of Abnormal Child Psychology, 26, 319-333.

Gorman-Smith, D., Tolan, P., Zelli, A., \& Huesmann, L. (1996). The relation of family functioning to violence among inner-city minority youths. Journal of Family Psychology, 10, 115-129.

Hirshi, T., \& Gottfredson, M. (1983). Age and the explanation of crime. American Journal of Sociology, 89, 552-584.

Jaffee, S. R., Caspi, A., Moffitt, T. E., Polo-Tomas, M., \& Taylor, S. (2007). Individual, family, and neighborhood factors distinguishing resilient from non-resilient maltreated children: A cumulative stressors model. Child Abuse and Neglect, 31, 231-253.

Lahey, B., Miller, T., Gordon, R., \& Riley, A. (1999). Developmental epidemiology of the disruptive behavior disorders. In B. Hankin \& J. Abela (Eds.), Development of psychopathology. Thousand Oaks, CA: Sage Publications.

Lahey, B. B., Van Hulle, C. A., Waldman, I. D., Rodgers, J. L., DiOnofrio, BmM., Pedlow, S. (...), Keenan, K. (2006). Testing descriptive hypotheses regarding sex differences in the development of conduct problems and delinquency. Journal of Abnormal Child Psychology, 34, 737-755.

Lahey, B. B., \& Waldman, I. D. (2005). A developmental model of the propensity to offend during childhood and adolescence. In D.P. Farrington (Ed.), Advances in criminological theory (Vol. 13, pp. 15-50) Piscataway, NJ: Transaction Publishers.

Laub, J. H., \& Sampson, R. J. (2001). Understanding desistance from crime. Crime and Justice, 28, $1-69$.

Lipsey, M. W., \& Derzon, J. H. (1999). Predictors of violent or serious delinquency in adolescence and early adulthood: A synthesis of longitudinal research. In R. Loeber \& D. P Farrington 
(Eds.), Serious and violent juvenile offenders: Risk factors and successful interventions (pp. 86-105). Thousand Oaks, CA: Sage Publications.

Loeber, R., \& Farrington, D. P. (2000) Young children who commit crime: Epidemiology, developmental origins, risk factors, early interventions and policy implications. Development and Psychopathology, 12, 737-762.

Loeber, R., Farrington, D. P., Stouthamer-Loeber, M., White, H. R., \& Wei, E. (2008). Violence and serious theft: Development and prediction from childhood to adulthood. New York, NY: Routledge.

Loeber, R., Wung, P., Keenan, K., Giroux, B., Stouthamer-Loeber, M., Van Kammen, W. B., \& Maughan, B. (1993). Developmental pathways in disruptive child behavior. Development and Psychopathology, 5, 103-133.

Luthar, S. S., \& Zigler, E. (1991). Vulnerability and competence: A review of research on resilience in childhood. American Journal of Orthopsychiatry, 61, 6-22

McCarthy, B., \& Hagan, J. (2001). When crime pays: Capital, competence, and criminal success. Social Forces, 79, 1035-1060.

McGue, M., Elkins, I., Walden, B., \& Iacono, W. G. (2005). Perceptions of the parent-adolescent relationship: A longitudinal investigation. Developmental Psychology, 41, 971-984.

Miech, R., Caspi, A., Moffitt, T., Wright, B., \& Silva, P. (1999). Low socioeconomic status and mental disorders: A longitudinal study of selection and causation during young adulthood. American Journal of Sociology, 104, 1096-1131.

Moffitt, T. E. (1990). The neuropsychology of juvenile delinquency: A critical review. In M. Tonry, $\&$ N. Morris (Eds.), Crime and Justice: Volume 12. Chicago, IL: University of Chicago Press.

Moffitt, T. E. (1993). Adolescence- limited and life- course persistent antisocial behavior: A developmental taxonomy. Psychological Review, 100, 674-701.

Moffitt, T. E. (2006). Life-course persistent versus adolescence-limited antisocial behavior. In D. Cicchetti \& D. J. Cohen (Eds.), Developmental psychopathology: Vol. 3 (2nd Ed.). Risk, disorder, and adaptation (pp. 570-598). New York, NY: Wiley.

Moffitt, T. E., \& Caspi, A. (2001). Childhood predictors differentiate life-course persistent and adolescence-limited antisocial pathways, among males and females. Development \& Psychopathology, 13, 355-375.

Moffitt, T. E., Caspi, A., Dickson, N., Silva, P. A., \& Stanton, W. (1996). Childhood-onset versus adolescent-onset antisocial conduct in males: Natural history from age 3 to 18. Development and Psychopathology, 8, 399-424.

Moffitt, T. E., Caspi, A., Harrington, H., \& Milne, B. (2002). Males on the life-course persistent and adolescence-limited antisocial pathways: Follow-up at age 26. Development \& Psychopathology, 14, 179-206.

Moffitt, T. E., Caspi, A., Rutter, M., Silva, P. A. (2001). Sex differences in antisocial behaviour: Conduct disorder, delinquency, and violence in the Dunedin Longitudinal Study. Cambridge, UK: Cambridge University Press.

Monahan, K. C., Steinberg, L., Cauffman, E., \& Mulvey, E. P. (2009). Trajectories of antisocial behavior and psychosocial maturity from adolescence to young adulthood. Developmental Psychology, 45, 1654-1668.

Nagin, D., \& Tremblay, R. E. (1999). Trajectories of boys' physical aggression, opposition, and hyperactivity on the path to physically violent and nonviolent juvenile delinquency. Child Development, 70, 1181-1196.

Patterson, G., Reid, J., \& Dishion, T. (1992). Antisocial boys. Eugene, OR: Catalia.

Rutter, M. (2003). Commentary: Causal processes leading to antisocial behavior. Developmental Psychology, 39, 372-378.

Rutter, M., Giller, H., \& Hagell, A. (1998). Antisocial behavior by young people. New York, NY: Cambridge University Press. 
Sameroff, A. (2007). Identifying risk and protective factors for healthy child development. In A. Clarke-Stewart, \& J. Dunn (Eds.), Families count. New York, NY: Cambridge University Press.

Shaw, D. S., Criss, M., Schonberg, M., \& Beck, J. (2004). The development of family hierarchies and their relation to children's conduct problems. Development and Psychopathology, 16, 483-500.

Steinberg, L., Blatt-Eisengart, I., \& Cauffman, E. (2006). Patterns of competence and adjustment among adolescents from authoritative, authoritarian, indulgent, and neglectful homes: A replication in a sample of serious juvenile offenders. Journal of Research on Adolescence, 15, 47-58.

Steinberg, L., \& Morris, A. S. (2001). Adolescent development. Annual Review of Psychology, 52, $83-110$.

Sterne, J., White, I., Carlin, J., Spratt, M., Royston, P., Kenward, M., Wood, A., \& Carpenter, J. (2009). Multiple imputation for missing data in epidemiological and clinical research: Potential and pitfalls. British Medical Journal, 338, b2393.

Tolan, P. H. (2009). Developmental-ecological understanding of relation of delinquency to adult offending for inner-city males. Powerpoint presented at Community Psychology Lunch of the University of Virginia, Charlottesville, VA.

Tolan, P. H., Guerra, N. G., \& Kendall, P. (1995). A developmental-ecological perspective on antisocial behavior in children and adolescents: Towards a unified risk and intervention framework. Journal of Consulting and Clinical Psychology, 63, 579-584.

Tolan, P. H., \& Gorman-Smith, D. (1992). Chicago Stress and Coping Interview Manual. Chicago: Families and Communities Research Group, Institute for Juvenile Research, The University of Illinois at Chicago.

Tolan, P. H., \& Gorman-Smith, D. (1993). Chicago Youth Development Study Community Scales. Chicago: Families and Communities Research Group, Institute for Juvenile Research, The University of Illinois at Chicago.

Tolan, P. H., Gorman-Smith, D., \& Henry, D. B. (2000). Chicago Youth Development Study Parenting Practices Measure: Instructions for Scaling Technical Report. Chicago: Families and Communities Research Group, Institute for Juvenile Research, The University of Illinois at Chicago.

Tolan, P. H., Gorman-Smith, D., \& Henry, D. B. (2001). Chicago Youth Development Study Community and Neighborhood Measure: Construction and Reliability Technical Report. Chicago: Families and Communities Research Group, Institute for Juvenile Research, The University of Illinois at Chicago.

Tolan, P. H., Gorman-Smith, D., \& Henry, D. B. (2002). Chicago Youth Development Study SelfReport Delinquency Scale Technical Report. Chicago: Families and Communities Research Group, Institute for Juvenile Research, The University of Illinois at Chicago.

Tolan, P., Gorman-Smith, D., \& Henry, D. (2003). The developmental ecology of urban males' youth violence. Developmental Psychology, 39, 274-291.

Tremblay, R. E., Pihl, R. O., Vitaro, F., \& Dobkin, P. L. (1994). Predicting early onset of male antisocial behavior from preschool behavior. Archives of General Psychiatry, 51, 732-739.

Tremblay, R. E., Nagin, D. S., Seguin, J. R., Zoccolillo, M., Zelazo, P. D., Boivin, M. (...), Jappel, C. (2004). Physical aggression during early childhood: Trajectories and predictors. Pediatrics, 114, e43-e50.

van Domburgh, L., Loeber, R., Bezemer, D., Stallings, R., \& Stouthamer-Loeber, M. (2009). Childhood predictors of desistance and level of persistence in offending in early onset offenders. Journal of Abnormal Child Psychology, 37, 967-980.

Wikstrom, P. H., \& Loeber, R. (2000). Do disadvantaged neighborhood cause well-adjusted children to become adolescent delinquents? A study of male juvenile serious offending, individual risk and protective factors, and neighborhood context. Criminology, 38, 1109-1142. 